\title{
Gas escape to crankcase: impact of system parameters on sealing behavior of a piston cylinder ring pack
}

\author{
Cristiana Delprete $^{1} \cdot$ Erjon Selmani $^{2}\left(\right.$ Arian Bisha $^{2}$
}

Received: 18 June 2018 / Accepted: 31 January 2019 / Published online: 11 March 2019

(c) The Author(s) 2019

\begin{abstract}
Internal combustion engines are the generators of energy for many transportation applications, but they still have an overall low efficiency due to mechanical and thermal losses. The combustion chamber is the core element of the engine and it ought to be perfectly sealed; however, some of the gas leaks toward the crankcase due to imperfect sealing of the rings. This leakage is known as blow-by and affects efficiency, correct lubrication and emissions. The aim of this paper was to understand, in a more detailed way, how some parameters could affect the sealing efficiency of a ring pack. In particular, ring gaps, ring masses and elastic properties, and ring static twists, were varied from the original and investigated for their influence on the inter-ring dynamics and sealing efficiency. The problem, referred to a turbo diesel engine, was formulated in terms of motion equations for the rings and gas equations for the inter-ring crevices, and solved in ${ }^{\circledR}$ Ricardo RINGPAK solver. The results were compared with the original design and with the reference literature. These results confirm that ring gaps and ring unstable motion have an important role in the phenomenon of gas blow-by. In addition, the second ring emerged to have a more important role on the blow-by reduction with respect to the top ring. However, this phenomenon is complex due to the interaction of several parameters, not all of which were included in this study. Nevertheless, these findings can already be taken into account for further studies or experimental investigations.
\end{abstract}

Keywords Blow-by $\cdot$ Internal combustion engines $\cdot$ Piston ring $\cdot$ Ring dynamics $\cdot$ Ricardo

\section{List of symbols}

A

$A_{\text {gap }}$

$A_{\mathrm{p}}$

$B$

BDC

$D$

E

$F_{\text {f }}$

$F_{\mathrm{i}}$

Erjon Selmani

erjon.selmani@polito.it

Cristiana Delprete

cristiana.delprete@polito.it

Arian Bisha

arian_bisha@hotmail.com

1 Politecnico di Torino, Torino, Italy

2 Universiteti Politeknik i Tiranës, Tirana, Albania
$F_{\text {gas }}, F_{\text {gas_back }}$ Gas pressure in radial direction on the ring section, $\mathrm{N}$

$F_{\mathrm{P}} \quad$ Gas pressure force in axial direction, $\mathrm{N}$

$F_{\text {Poil }}$

$F_{\mathrm{S}} \quad$ Oil squeeze force in the grove, $\mathrm{N}$

$F_{\text {Tension }}$

$f^{\prime \prime} \quad$ Ring gap at free condition, $\mathrm{m}$

$f_{\mathrm{m}} \quad$ Flow coefficient

$h \quad$ Oil film thickness, $\mu \mathrm{m}$

I Moment of inertia for ring section, $\mathrm{kg} \mathrm{m}^{2}$

$L \quad$ Ring length, $m$

$m \quad$ Mass of gas in the $i$ th region, $\mathrm{kg}$

$m_{\mathrm{r}} \quad$ Mass of the ring, $\mathrm{kg}$

$M_{\text {gas }}$

$M_{\text {gr_oil }}$

$M_{1 \_ \text {oil }}$

$M_{\text {pre }}$
Moment due to gas pressure distribution, $\mathrm{Nm}$

Moment due to oil pressure in the groove, $\mathrm{Nm}$

Moment due to oil pressure in the cylinder liner, $\mathrm{Nm}$

Moment due to ring pretwist, $\mathrm{Nm}$ 


$\begin{array}{ll}\text { od, id } & \text { Ring outer and inner diameter, } \mathrm{m} \\ U & \text { Piston velocity, } \mathrm{m} / \mathrm{s} \\ \text { uhc } & \text { Unburned hydrocarbons } \\ P & \text { Pressure, Pa } \\ P_{\mathrm{U}}, P_{\mathrm{D}} & \text { Pressure up and down the gap, Pa } \\ P_{\text {oil }} & \text { Pressure due to oil film thickness, Pa } \\ Q_{\mathrm{in}}, Q_{\text {out }} & \text { Mass flow entering and exiting a crevice, } \\ & \mathrm{kg} / \mathrm{s} \\ Q_{\text {gap }} & \text { Mass flow through the ring gap, } \mathrm{kg} / \mathrm{s} \\ R & \text { Ideal gas constant, } \mathrm{J} / \mathrm{kgK} \\ T & \text { Temperature, } \mathrm{K} \\ \mathrm{TDC} & \text { Top dead center } \\ V & \text { Volume, } \mathrm{m}^{3} \\ V_{\mathrm{p}} & \text { Piston velocity, } \mathrm{m} / \mathrm{s} \\ x, y & \text { Axial and radial position of the ring, } \mathrm{m} \\ \alpha, \alpha_{0} & \text { Ring twist angle in work and in static con- } \\ \gamma & \text { ditions, }{ }^{\circ} \\ \tau & \text { Specific heat ratio } \\ \tau & \text { Hydrodynamic shear stress, } \mathrm{N} / \mathrm{m}^{2} \\ \mu & \text { Oil dynamic viscosity, Pa/s } \\ \sigma^{\prime \prime}{ }_{\mathrm{b}} & \text { Bending stress, } \mathrm{PA}\end{array}$

\section{Introduction}

According to the World Energy Council [1], despite the growing use of electrical propulsion systems, internal combustion engines will still be widely employed in the next decades. The power obtained in the engine's combustion chamber is transferred to the user by means of the piston and connecting rod. Piston rings main duty is to seal off the combustion chamber; however, their tightness is not perfect and part of the intake gas mixture is lost toward the crankcase, a phenomenon which is commonly known as blow-by gas. In addition, part of these gasses can return to the combustion chamber (blow-back) and be ejected as unburned hydrocarbons. Blow-by has an overall detrimental effect on performances due to the reduction of peak pressure [2], and on lubrication and emissions due to oil transport [3-6]. Several studies have addressed the phenomenon of blowby. Furuhama et al. [7] and Namazian et al. [8] were the first to formulate the problem equations and provide experimental evidence of the influence of ring axial motion (also called axial flutter) on the tightness capacity. However, their analysis did not provide the motion of the rings in other directions. Keribar et al. [9] and Wannatong et al. [10] provided more complete formulations, including also aspects of lubrication and surface properties. As an important gas escape orifice, Tomanik et al. in [12] investigated the influence of the top ring end-gap reduction on blow-by, where they found that reducing the top ring gap can be helpful in the gas flow reduction. However, they did not explain the impact on the second ring dynamics, whose gap effect was not treated in that work. Lijima et al. [13] and Przesmitzki et al. [14] experimentally observed the ring radial motion and defined the phenomenon of the ring radial collapse as a contact lift-off between ring face and cylinder liner. Both references $[13,14]$ state that increasing the speed and load of the engine increases the possibility for the rings to undergo a radial collapse; however, no mention was made on the impact of the radial force exerted by the rings. Tian in [15, 16] analyzed the ring twist in the ring dynamic model, and according to results the ring twist can significantly affect both axial and radial dynamics. Positive static twists can bring benefits in terms of sealing efficiency, while negative static twists may lead rings to axial flutter, which can also be a desired effect in certain conditions. However, a combined scheme of the twist angles was not indicated. The effect of ring twist angle on the ring dynamics was also discussed by Rabutè et al. [17] and Cheng et al. [18].

This study deals with the impact of three parameters on the tightness capacity of a ring pack: ring gap variation, ring masses and elastic force variation, ring static twist variation. In literature, similar analyses have mainly considered the top ring, while in the present work the focus was also on the second ring. The mathematical model of the problem was formulated in terms of ring and gas dynamics and solved in CRicardo RINGPAK. The analysis was applied to a turbo diesel engine and performed at full load condition and at two different engine speeds. The performance of the ring pack was evaluated in terms of inter-ring pressures, ring dynamics, inter-ring gas flows and blow-by gases.

The results for the three cases were compared with the original design and with literature, and conclusions were carried out.

\section{Modeling approach for gas dynamics}

Piston rings are curved beams with an end gap; Fig. 1. This allows the mounting operation and ensures a radial force toward the cylinder liner. This force is an important element of the sealing capability of a ring, while the gap is the main

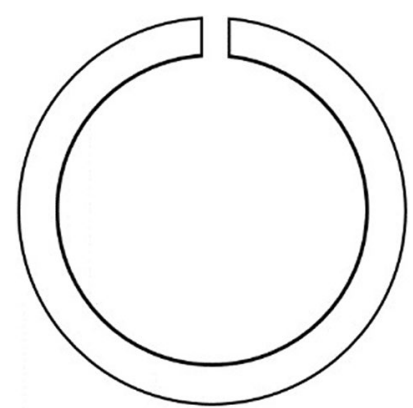

Fig. 1 Piston ring 


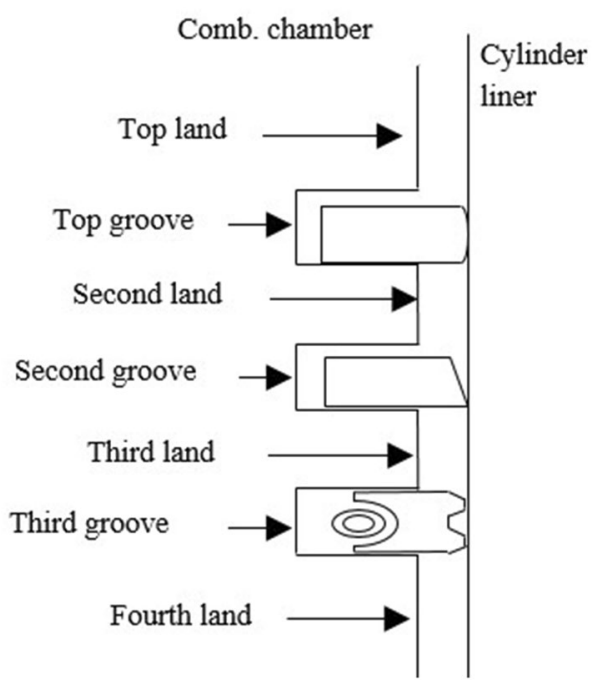

Fig. 2 Schematic of piston, ring pack and cylinder liner

escape route for the gas. The standard solution for automotive applications is a three-ring pack, composed of two compression rings and one oil ring, although in the literature other solutions have been proposed [19]. To account for thermal expansion and groove distortion, the ring axial width is smaller than the respective groove height; Fig. 2 [21]. This clearance is responsible for an additional route for the gas to escape when the rings are in motion.

To compute the pressure distribution in each zone, the ideal gas Eq. (1) is coupled with the continuity Eq. (2) [9].

$\left(\frac{\mathrm{d} p}{\mathrm{~d} t} v+\frac{\mathrm{d} v}{\mathrm{~d} t} p\right)=\left(\frac{\mathrm{d} m}{\mathrm{~d} t}\right) R T+m R\left(\frac{\mathrm{d} T}{\mathrm{~d} t}\right)$,

$\frac{\mathrm{d} m}{\mathrm{~d} t}=Q_{\text {in }}-Q_{\text {out }}$

The flow through the gap can be modeled using the orificeflow model for a laminar and compressible flow [10].

$Q_{\text {gap }}=\frac{C_{\mathrm{D}} A_{\mathrm{gap}} P_{\mathrm{U}}}{\sqrt{R T_{\mathrm{U}}}} f_{\mathrm{m}}$,

where $f_{\mathrm{m}}$ has the following expression:

$$
\begin{aligned}
& f_{\mathrm{m}}=\left(\frac{P_{\mathrm{D}}}{P_{\mathrm{U}}}\right)^{\frac{1}{\gamma}}\left\{\left(\frac{2 \gamma}{\gamma+1}\right)^{\frac{\gamma+1}{2(\gamma+1)}}\left[1-\left(\frac{P_{\mathrm{D}}}{P_{\mathrm{U}}}\right)^{\frac{\gamma-1}{\gamma}}\right]\right\}^{\frac{1}{2}} \\
& \text { for } \frac{P_{\mathrm{D}}}{P_{\mathrm{U}}}>\left(\frac{2}{\gamma+1}\right)^{\frac{\gamma}{\gamma-1}} ;
\end{aligned}
$$

or when the flow is chocked,

$$
f_{\mathrm{m}}=\gamma^{\frac{1}{2}}\left(\frac{2}{\gamma+1}\right)^{\frac{\gamma+1}{2(\gamma+1)}} \text { for } \frac{P_{\mathrm{D}}}{P_{\mathrm{U}}} \leq\left(\frac{2}{\gamma+1}\right)^{\frac{\gamma}{\gamma-1}} \text {. }
$$

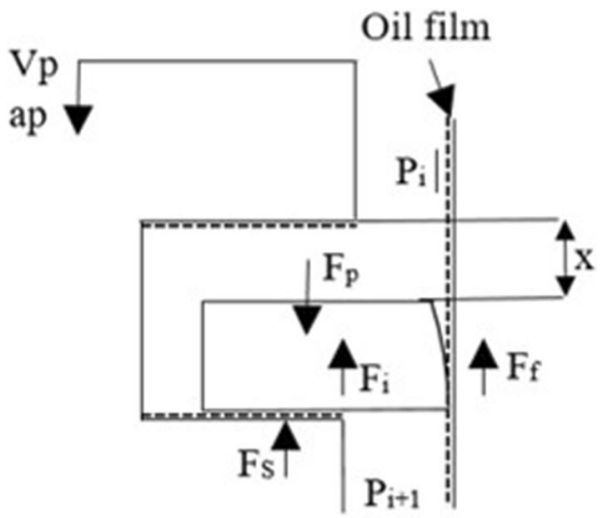

Fig. 3 Forces in axial direction

The discharge coefficient can be calculated using the following equation [10]:

$C_{\mathrm{D}}=0.85-0.25\left(\frac{P_{\mathrm{D}}}{P_{\mathrm{U}}}\right)^{2}$

Often, Eq. (1) is simplified with respect to the differentials of volume and temperature. These simplifications are justified by the fact that volume variation in the different inter-ring crevices is negligible compared to the combustion chamber volume. In addition, our model referred is rigid and does not include deformations of the components. Furthermore, two different assumptions are usually made for the gas temperature $[7,8]$. It can be considered to have an adiabatic distribution and thus be calculated for each step of the solution, or have an isothermal distribution and thus be equal to the temperature of the surrounding walls. Experimental results in $[7,8]$ showed that the isothermal assumption is closer to the reality; this assumption was also made in the present paper.

\section{Modeling approach for ring dynamics}

Inside the groove, the piston ring has three degrees of freedom, axial, radial and toroidal (torsion around its central axis); hence, it is necessary to write the equilibrium equations for each direction of motion. Figures 3 and 4 give all the forces assumed to act on the ring cross section in the axial and radial direction, while Fig. 5 shows the moments acting on the ring section.

Consequently, the equilibrium equations (Newton second law) for axial, radial and toroidal motion can be written according to Eqs. (7)-(9) [9]:

$m_{\mathrm{r}} \frac{\mathrm{d}^{2} x}{\mathrm{~d} t^{2}}=F_{\mathrm{P}}-F_{\mathrm{i}}-F_{\mathrm{s}}-F_{\mathrm{f}}$,

$m_{\mathrm{r}} \frac{\mathrm{d}^{2} y}{\mathrm{~d} t^{2}}=F_{\mathrm{gas}_{\mathrm{back}}}+F_{\text {tension }}-F_{\text {gas }}-F_{\text {Poil }}$, 


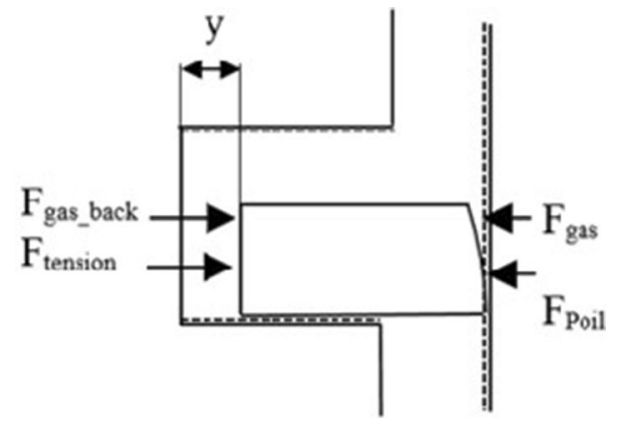

Fig. 4 Forces in radial direction

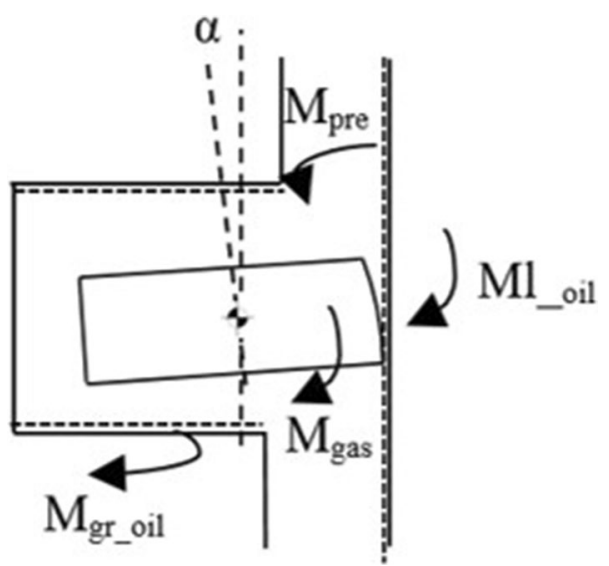

Fig. 5 Moments around the central axis

$I \frac{\mathrm{d}^{2} \alpha}{\mathrm{d} t^{2}}=M_{\text {gas }}+M_{\text {gr_oil }}+M_{1 \_ \text {oil }}-M_{\text {pre }}$.

In Fig. 5, the tilt angle $\alpha$ can be noticed; this angle is considered positive when the ring is tilted anticlockwise. The inertial force in the radial direction and inertial moment have not been considered in this study due to their low magnitude. Additionally, assuming that the contact in the ring-groove and the ring-liner interface is always flooded with lubrication oil, the asperity forces and moments have not been taken into account.

The pressure distribution due to the oil film can be determined through the one-dimensional Reynolds equation:

$\frac{\partial}{\partial x}\left(h^{3} \frac{\partial P_{\mathrm{oil}}}{\partial x}\right)=6 \mu U \frac{\partial h}{\partial x}+12 \mu U \frac{\partial h}{\partial t}$.

Once the oil pressure has been calculated, the hydrodynamic force, hydrodynamic shear stress and viscous friction exerted on the ring section can be obtained [10]:

$F_{\text {Poil }}=P_{\text {oil }} \times A$, $\tau=\frac{-\mu U}{h}+\frac{h}{2} \frac{\mathrm{d} P_{\mathrm{oil}}}{\mathrm{d} x}$

$F_{\mathrm{f}}=\tau \times A$.

The ring elastic force (ring tension) is the force exerted against the cylinder liner and can be obtained from the curved beam theory [11]:

$F_{\text {Tension }}=p_{\text {tension }} \times A$,

$p_{\text {tension }}=\frac{1}{3}\left(\frac{\sigma_{\mathrm{b}}^{\prime \prime} \times b^{2}}{D(D-b)}\right)$,

$\sigma_{\mathrm{b}}^{\prime \prime}=\frac{3}{2}\left(\frac{E b f^{\prime \prime}}{L^{2}}\right)$

Finally, the torsional ring stiffness and the moment due to ring torsion can be calculated from the following equations [10]:

$$
\begin{gathered}
T_{\mathrm{r}}=\frac{E b^{3} \ln \left(\frac{D_{\mathrm{o}}}{D_{\mathrm{I}}}\right)}{3\left(D_{\mathrm{o}}+D_{\mathrm{I}}\right)}, \\
M_{\text {pre }}=T_{\mathrm{r}}\left(\alpha-\alpha_{0}\right) .
\end{gathered}
$$

\section{Simulation}

According to the equations described above, the inter-ring dynamics, inter-ring pressures and gas flows, can be affected by a large number of parameters. These parameters can be operational (speed, load, temperature), mechanical (material, elastic modulus, thermal conductivity), may depend on design (areas, volumes) or may also depend on the properties of the lubrication oil and surface textures.

In each of the Eqs. (7)-(9), equilibrium is dependent on the applied forces and moments. In the axial direction, the main forces are gas pressure and inertia and, when they are comparable in magnitude, the ring position may be unstable and be subject to axial flutter [8]. Under these conditions, the ring loses its sealing capacity and gases can bypass the ring, flowing through the groove channel. In the radial direction, the gas pressure on the ring back is supported by the hydrodynamic pressure in the oil film. The ring tension force is necessary to guarantee a constant static force, since the groove pressure changes through the cycle. In certain conditions, the gas force exerted on the exposed ring face can overcome the outward forces and push the ring inside the groove. This phenomenon is called radial collapse and when it occurs, gas flows directly between the ring face and 


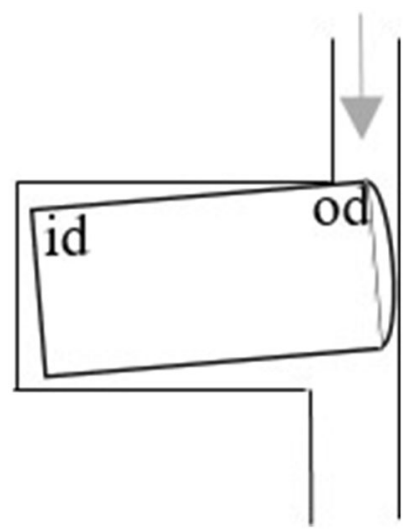

Fig. 6 Positive twist angle

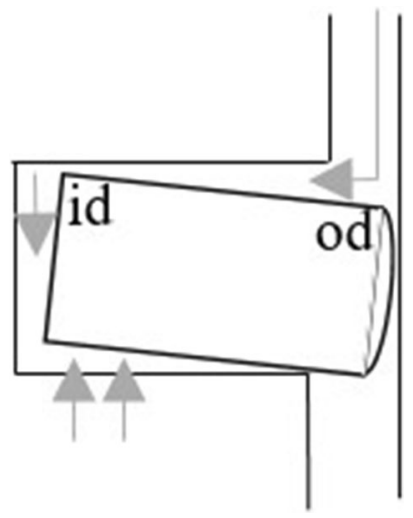

Fig. 7 Negative twist angle

cylinder liner [13]. The twist angle of the ring affects in a different way the sealing capability of the ring pack. According to Fig. 6, [15, 16], when the ring has a positive twist angle, the gas flow is blocked by the ring outer diameter, which makes contact with the upper flank of the groove. As a consequence, high-pressure gases act mainly in a downward direction and the ring is forced to the bottom of the groove, thus sealing the flow. Figure $7[15,16]$ gives the gas flow when the ring has a negative twist angle, allowing the gas to enter through the groove and under its lower surface. If the gas pressure is high enough, it can push and lift the ring upward.

The number of parameters affecting the sealing efficiency of a ring pack is high, so it would be extremely difficult to consider all of them in the space of a scientific paper, hence the decision to study the phenomenon by splitting the parameters. In previous works [20], the authors investigated the effect of speed, load and inter-ring volumes, on the sealing capacity of a ring pack, while in this work extending the study to other parameters has been proposed. First of all, it was decided to simulate the effect of the top and second
Table 1 Gap variation

\begin{tabular}{lrr}
\hline Case 1 & Gap-R1 & Gap-R2 \\
\hline 1 & $-30 \%$ & $+30 \%$ \\
2 & $+30 \%$ & Original \\
3 & $-30 \%$ & $-10 \%$ \\
\hline
\end{tabular}

Table 2 Mass and tension variation

\begin{tabular}{llcl}
\hline Case 2 & Speed & Ring masses & Ring tensions \\
\hline 1 & Med & $+100 \%$ & $+58 \%,+74 \%$ \\
2 & High & $+100 \%$ & $+58 \%,+74 \%$ \\
\hline
\end{tabular}

Table 3 Static twist variation

\begin{tabular}{lll}
\hline Case 3 & St. Twist-R1 & S.Twist-R2 \\
\hline 1 & $0.3 \Rightarrow 0.5$ & $0 \Rightarrow 0.3$ \\
2 & $0.3 \Rightarrow-0.5$ & $0 \Rightarrow-0.3$ \\
3 & $0.3 \Rightarrow 0.5$ & $0 \Rightarrow-0.5$ \\
\hline
\end{tabular}

ring gaps. The gaps were changed according to the values given in Table 1. Higher values may be a consequence of the wear rate, while lower values are imposed by thermal constraints. Secondly, a different material was chosen for the top two rings with respect to the original design, with higher tension but also higher ring masses, as indicated in Table 2. For this case, the simulation was run with two levels of speeds, medium (2000 rpm) and high (4500 rpm), with the aim of studying the tightness of the compression rings in the radial direction under severe working conditions. Lastly, it was decided to change the twist angle of the rings, proposing three different configurations, as given in Table 3 . The proposed values are in line with those obtained for rings when the grooves are deformed, the wear course is significant, liner distortion is high or, more likely, when all three of these factors are present. In all three cases, the third ring was left unchanged with respect to the original design, due to its low impact on the sealing.

Simulations are performed considering a direct injection turbo diesel engine with $0.125 \mathrm{~m}$ bore and $0.27 \mathrm{~m}$ stroke. The ring pack is composed of three rings: a barrel-face top ring with $0.3^{\circ}$ twist angle, a taper face second ring and a mono-piece and spring-loaded oil ring, both with $0^{\circ}$ twist angle. The minimum oil film thickness is assumed to be $5 \mu \mathrm{m}$. The nominal working conditions for the current engine are $2000 \mathrm{rpm}$ at full load, also used in the baseline condition and in all except one of the other simulations.

The input data are implemented in ${ }^{\circ}$ Ricardo RINGPAK solver. RINGPAK is a simulation suite for the analysis of a piston ring pack. It uses an integrated modeling approach to calculate friction, lubrication, wear, blow-by, and oil 
consumption. In addition to the geometrical data, the user interface requires further information such as groove and land temperatures, liner temperature and oil properties, crankcase pressure and temperatures. For the present study, a 2D-axial symmetric analysis was selected, where the components involved were considered rigid. Furthermore, piston secondary motion and bore distortion were also neglected.

\section{Results and discussion}

In this section, the results of the simulations are presented and grouped for each case. Results include the position of the rings in the grooves, inter-ring pressures, ring-liner clearances, mass flow rates of gas in the different grooves and the total blow-by, expressed as the amount of gas that is lost in the crankcase room. Initially, the results for the baseline case will be discussed, and subsequently the results for cases one, two and three, respectively.

\section{Baseline case}

Figure 8 shows the results of the simulations for the baseline case. In Graph 8a, the inter-ring pressure in the piston lands is given. Top land pressure is equal to the combustion chamber pressure, and fourth land pressure is equal to the crankcase pressure. The first engine phase of the diagram is compression, as confirmed by the typical pressure curve.
The pressure rise in the second land follows the peak combustion pressure with a certain delay, then, at the end of the expansion stroke, the pressure in the second land surpasses the combustion chamber pressure at the so-called crossover point. After this point, both curves show a decreasing trend, except for the top land pressure, which slightly rises by the end of the exhaust stroke, but then drops again in correspondence to the intake stroke, when piston changes direction. The third land pressure never reaches the second land pressure, but its trend follows almost exactly that of the pressure in the second land. The pressure in the fourth land is equal to the crankcase pressure and almost equal to the ambient pressure.

Figure $8 \mathrm{~b}$ gives the relative positions of the rings in the respective grooves, where 0 means the ring is seated at the bottom of the groove and 1 means at the top. According to Fig. 8b, the top ring remains seated during the compression and expansion strokes and rises initially at the end of the expansion stroke, in correspondence to the crossover point, when the pressure in the second land becomes higher than pressure in the first land. From the half of exhaust stroke to the half of intake stroke, the top ring is lifted and then goes back down to the bottom at the end of the intake stroke. The first lift is caused only by the pressure force as described above, while the second and longer lift is produced mainly by the inertia force. The second ring stays on the lower groove flank during the entire cycle, while the third ring rises during the expansion stroke, driven mainly by the (a)

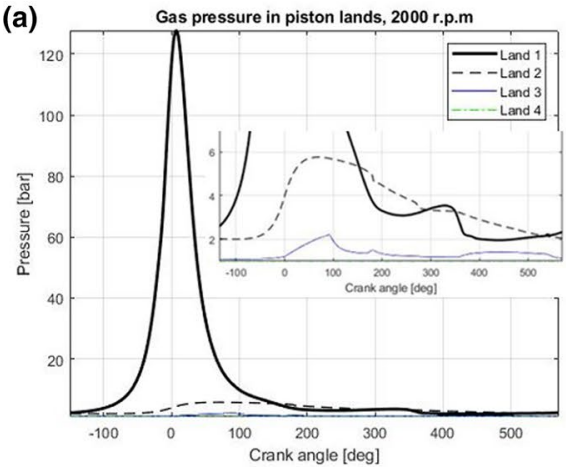

(d)

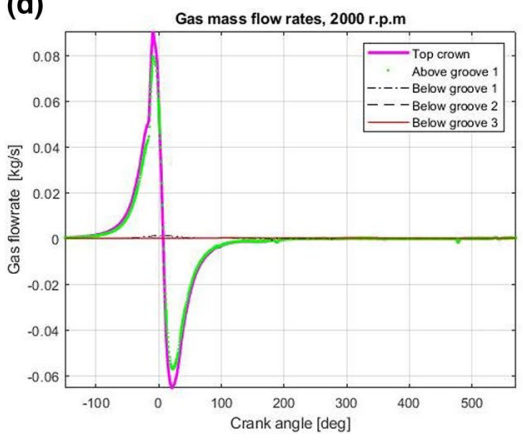

(b)

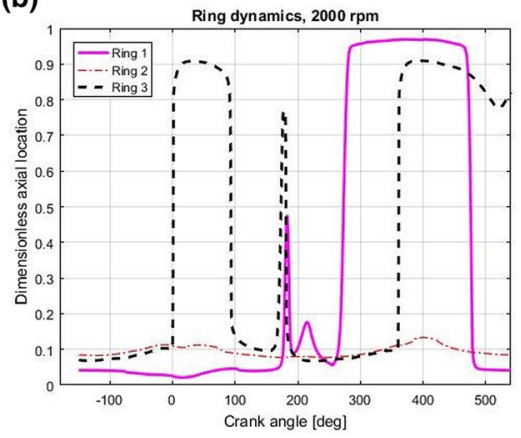

(e)

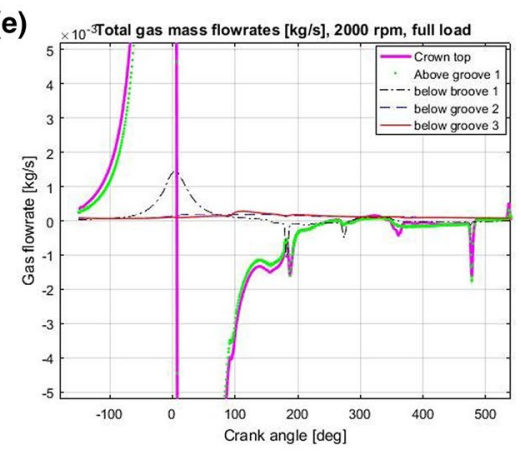

(c)
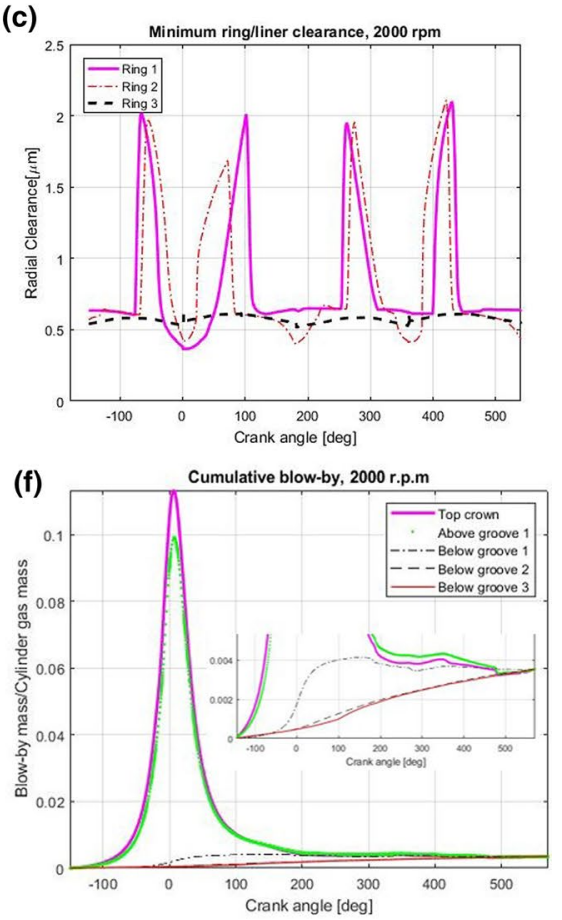

Fig. 8 Results for the baseline case 
inertia and oil friction forces, since the pressure force on this ring is low when compared to the others.

The minimum oil film thickness in the cylinder liner was assumed equal to $5 \mu \mathrm{m}$, and in Fig. 8c the ring-liner clearances are given. According to the figure, each ring face is always flooded with the oil film and there is always contact between the ring face and cylinder liner.

In Fig. 8d and more in detail in Fig. 8e are given the total mass flow rates of gas in each groove. Positive values are the downward flows from the upper lands, and negative values are the upward or back flows from lower lands. The largest amount of gas flow rates occurs in the top land and top groove; this result is expectable due to the high pressure in these regions.

Furthermore, the gas flow below the second groove goes entirely in the third land and from the third land in the crankcase, confirmed by the absence of back flow to the upper lands.

In Fig. 8f, the cumulated blow-by for each curve of flow described above is given, expressed as a fraction of the cylinder gas mass at BDC. Under these working conditions, roughly $12 \%$ of the cylinder mass entered the top land and groove crevice during the power stroke, without taking part in the combustion. $0.4 \%$ of this gas mass finished in the crankcase as blow-by gas, which for this simulation corresponded to $0.0103117 \mathrm{~kg} /$ cycle.

\section{Gap variation}

The graphs in Fig. 9 show the results for the variation in gaps and are laid out in a top-down direction for each subcase, according to Table 1.

In Fig. 9a.1, the inter-ring pressures for case 1 are given, where the top ring gap is reduced and the second ring gap is increased. The general trend of the first land pressure curve is similar to the baseline case, where the most relevant difference is observed in the slight rise of this curve at the end of the expansion stroke at angles $280^{\circ}-350^{\circ}$. This is caused by the higher pressure in this land in comparison to the baseline case, because the reduction of the top ring gap leads to benefits in terms of a reduction of the downward gas flow. This benefit is confirmed through the lower peak pressure in the second land and delay with few degrees of the crossover point, compared to the baseline condition. However, the increment of the second ring gap allows higher gas flow rates to the third land, as confirmed by the higher peak pressure in this land. From Fig. 9b.1, the top ring lift is reduced noticeably due to the lower second land pressure, and occurs only in correspondence to the second crossover point. The second ring maintains the same seated position as in the baseline case, while the third ring motion is similar to the baseline with the only exception of a drop at the end of the intake stroke. The curve of the gas flow rate for this subcase is given in Fig. 9c.1, and the total blow-by gas lost in the crankcase is equal to $0.01386 \mathrm{~kg} / \mathrm{cycle}$.

Figure 9a.2 shows the inter-ring pressures for subcase 2, when only the top ring gap is increased by $30 \%$. A larger amount of gas flows in the second land due to the larger gap area and subsequently increases the pressure in this region. Due to the higher gas pressure in the second land, the crossover point was anticipated in time and the third land pressure increased, as confirmed by the graph. The ring motion for this case is shown in Fig. 9b.2. Due to the high pressure in the second land, the top ring lifted in correspondence to the crossover point and stayed at the top of the groove for a longer time, due to the high upward force acting beneath it. The second ring did not change its position in the groove during the cycle, while the motion of the third ring was similar to the base case, but with a lower attitude to move at the end of the expansion stroke. According to Fig. 9c.2, the total blow-by gas lost in the crankcase for this condition was equal to $0.01405 \mathrm{~kg} / \mathrm{cycle}$.

Figure 9a. 3 gives the pressure curves for subcase 3 of this section, where the top ring gap was reduced by $30 \%$ and the second ring gap was reduced by $10 \%$. This change led to a positive effect in terms of inter-ring gas pressures, because the second and the third land pressures reached the lowest values of the three subcases. Furthermore, the second land pressure never surpassed the top land pressure and, as a result, the effect on the top ring motion was greatly reduced. However, in Fig. 9b.3, it is possible to notice an unstable position of the second ring, which was subject to axial flutter and had the tendency to frequently change its position in the groove. This behavior is due to the reduced effect of the pressure force, and subsequent increased effect of the inertia force, now comparable in magnitude. The top ring was always in contact with the lower groove flank; it moved to the upper flank at the beginning of the intake stroke when the second land pressure equaled the top land pressure, allowing inertia to take advantage. The motion of the third ring appeared to obey only the inertia force, confirmed by the extremely low pressure reached in the third land. According to Fig. 9c.3, the total blow-by gas lost in the crankcase for this condition is equal to $0.00349 \mathrm{~kg} / \mathrm{cycle}$ and is the lowest value in this section. In this section, the graph of the radial clearance was omitted because the rings always made contact with the liner.

The results confirm that the ring gaps are important gas escape orifices. The reduction of the top ring gap allows a smaller amount of gas to flow toward the second land, in line with the results obtained in [12]. The increment of the top ring gap has the opposite effect, because the gas flowing from the top land will increase the pressure in the second land, and subsequently this pressure will act on both the top and second ring flanks. In addition to the reference, ring gaps affect not only the gas flow, but also the ring motion. It 
(a1)

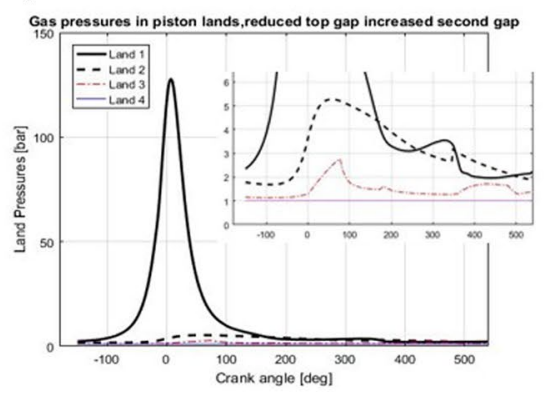

(b1)

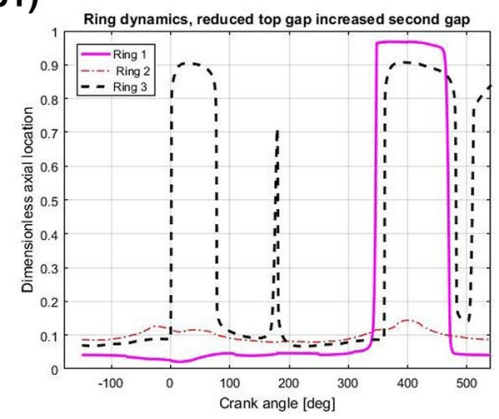

(c1)

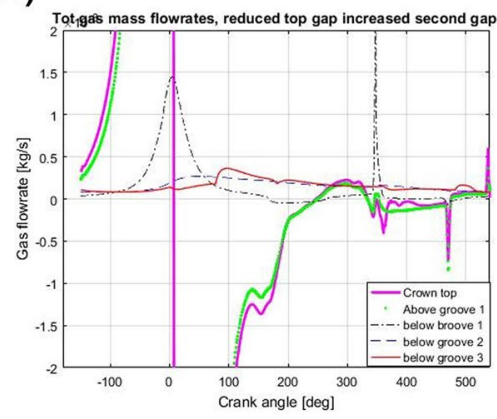

(a2)

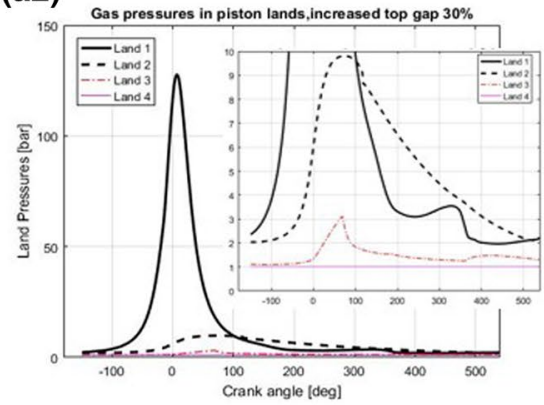

(b2)

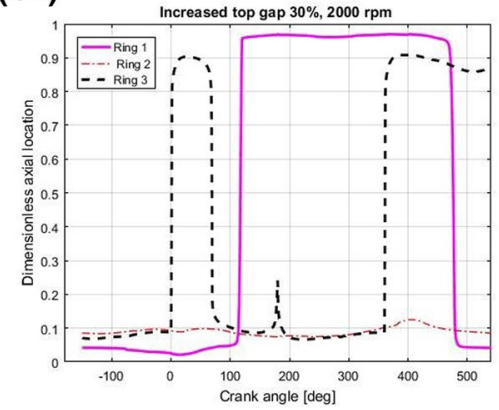

(c2)

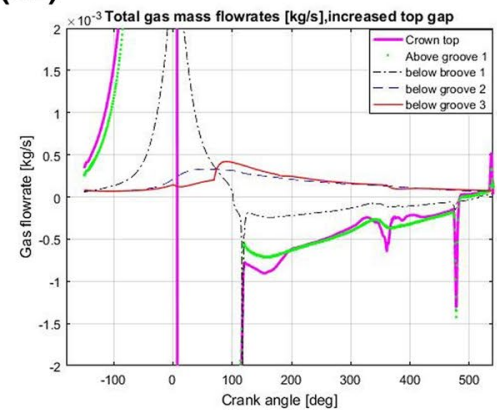

(a3)

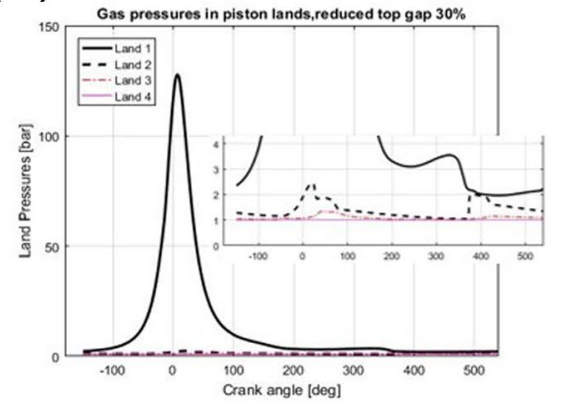

(b3)

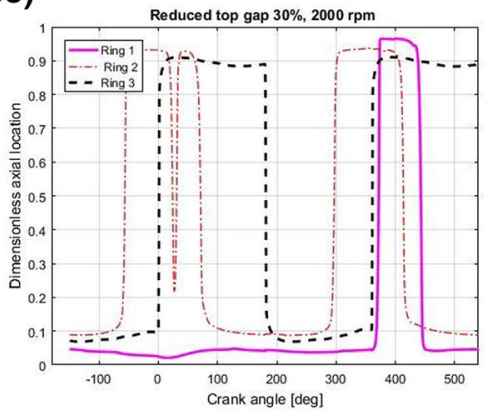

(c3)

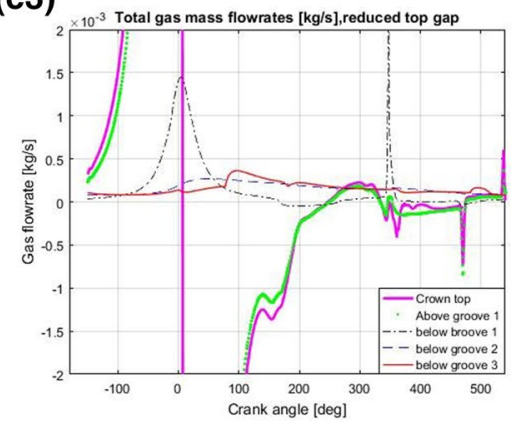

Fig. 9 Results for the gap variation, case 1

is possible to verify from the figures that each ring motion is associated with a pressure variation in the land pressure curve. However, the second ring gap also plays an important role, as confirmed by the simulations. Large second ring gaps allow higher gas flow rates toward the third land, while small second ring gaps do the opposite. A high second land pressure will make the top ring lift more frequently, and the second ring sits for a longer time. The effect of the top ring gap on the second ring dynamics is similar to the effect of the second ring gap on the third ring dynamics. The combination of these two parameters should be decided according to the objectives to be achieved. If the aim is to limit the blow-by gas in the crankcase, it is recommended to reduce both ring gaps, even if the stability of the second and third rings may be affected.

\section{Mass and elasticity variation}

Figure 10 gives the results of the simulations when the top compression rings are changed with new ones, made of a heavier material and with an increased tension force, as described in Table 2.

In Fig. 10a.1, the inter-ring pressures for speed level $2000 \mathrm{rpm}$ are depicted. In comparison to the baseline scenario, peak pressures in the second and third lands are slightly lower, equivalent to an increased sealing capability of the ring pack. Furthermore, the pressure curve in the second land is not continuous during its rise, but shows a slight fall in correspondence to the end of the compression stroke, at the same time as the third land pressure shows a slight rise. In Fig. 10b.1, the ring motions for this case are given. The top ring is more stable than the baseline case, showing only one lift from the middle of the exhaust stroke to the middle of the intake stroke. As described in 

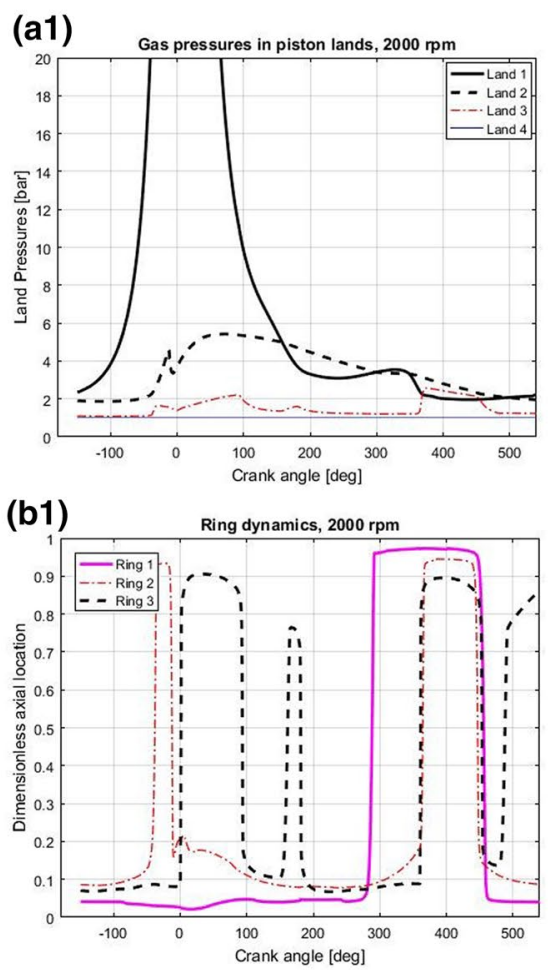

(c1)

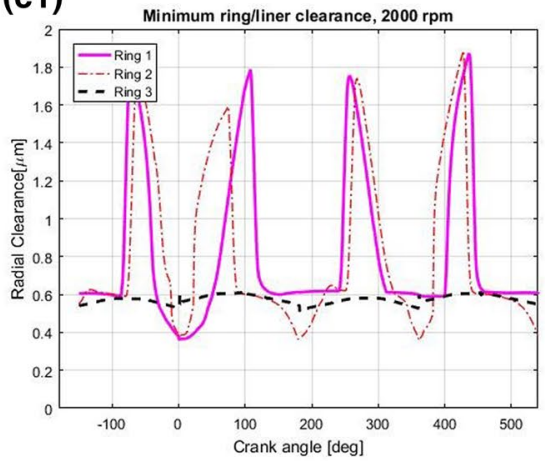

(a2)

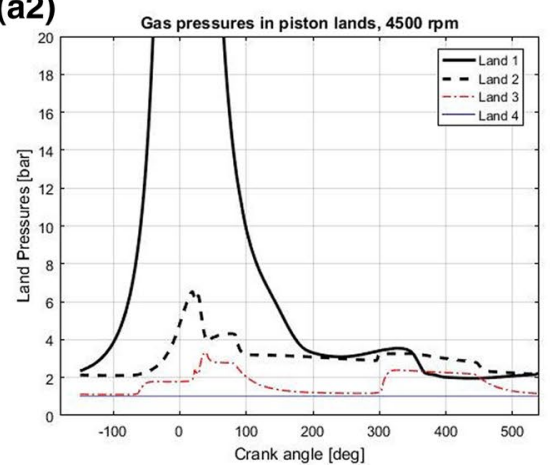

(b2)

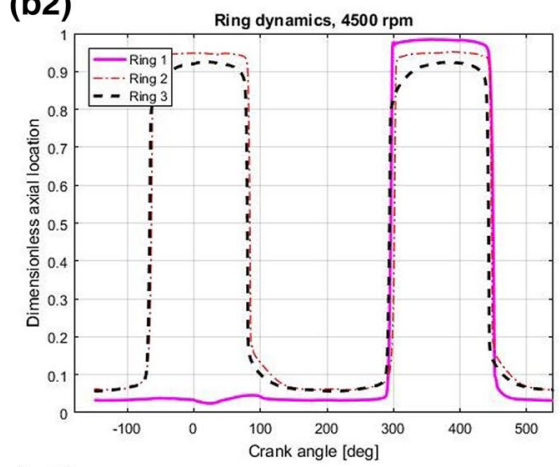

(c2)

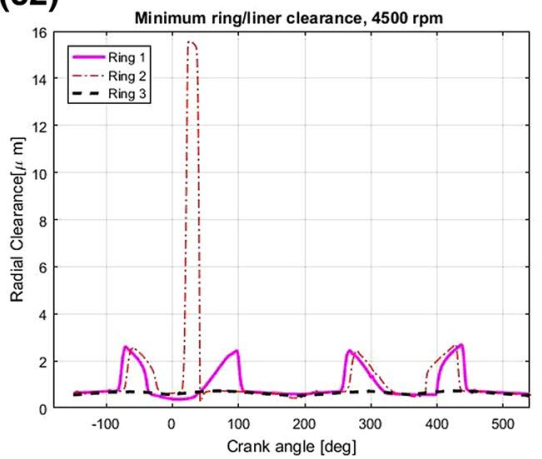

(d1)

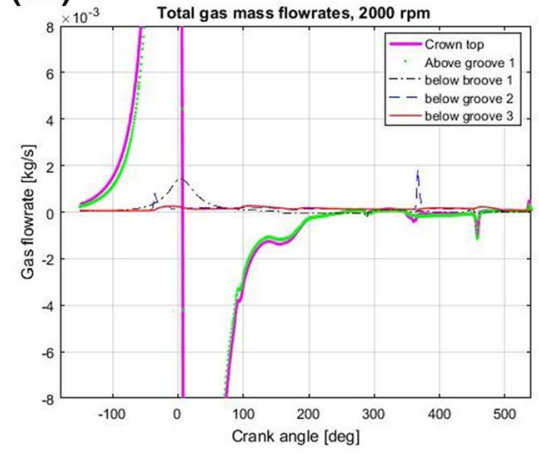

(d2)

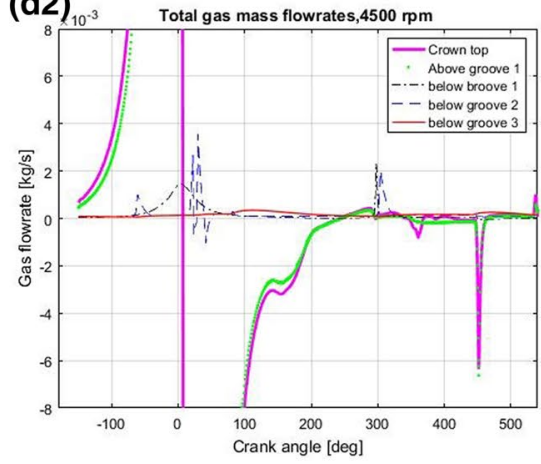

(d3)
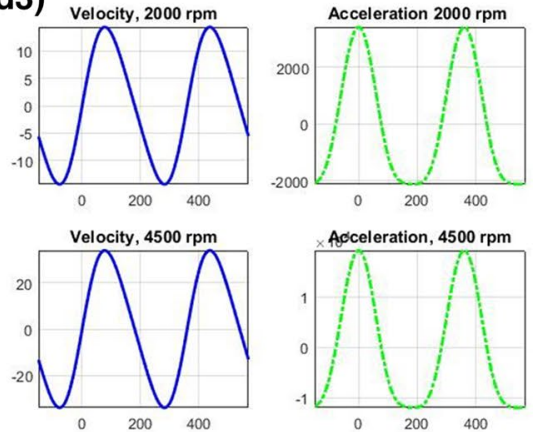

Fig. 10 Results for mass and tension variation, case 2

the graph, this lift is not in correspondence to the crossover point, but in correspondence to the point where the pressure in the second land is equal to the top land, which means that the motion is driven by inertia and the higher ring tension force, which is now responsible for a higher oil friction force acting always in the opposite direction to the ring motion. The second ring, instead, undergoes axial position variation, with the first rise at the end of the compression stroke when the pressure in the second land is still low, and a second rise at the beginning of the intake stroke only due to inertia. Regardless of the higher tension for this ring in comparison to the baseline case, the inertia force proved to be dominant and forces the ring to lift in two different strokes. Another reason is related to the ring face design: due to the scrape function, taper-faced rings have a smaller contact surface with the oil film and leave a higher contact surface to the gas pressure [13]. In this case, the increase of the ring tension has less effect on the ring motions when compared to the barrel-face top ring.

The first rise causes a light pressure increase in the third land, indicating that when the ring is moving a larger amount of gas can flow in the nearby region. The third ring did not change its characteristics and thus its motion was almost similar to previous cases. Figure 10c.1 shows the radial clearance graph where it is possible to notice that all three rings maintained contact with the liner surface during the entire cycle.

Figure 10a.2 shows the inter-ring pressure graph when the simulation is run with $4500 \mathrm{rpm}$ engine speed. In comparison to the previous case, the pressure in the second land 
had a fast rise and a subsequent sharp drop immediately after the peak pressure. In addition, the second land pressure did not surpass the top land pressure until the intake stroke. On the other hand, the pressure in the third land followed the pressure in the second land, with the only exception of a rise when the drop in the second land occurred. The peak pressure in the second land was higher than the peak pressure of the previous case, but after the drop the pressure value remained almost constant. Conversely, the third land pressure maintained a higher pressure after the drop occurred. In Fig. 10b.2, the ring motions for this case are given. The top ring motion was almost identical, while the second and third rings made two lifts, at the same position and for the same crank angle of the cycle. These lifts both occurred in proximity to the TDC; nonetheless, none of the lifts could explain the pressure drop seen in the second land and the rise in the third land. To give an explanation, it is necessary to observe in Fig. 10c. 2 the radial clearances. The top and the third ring faces are always in contact with the cylinder liner, but the second ring radial clearance to the cylinder liner reached almost $16 \mu \mathrm{m}$ compared to the $5 \mu \mathrm{m}$ of the oil film thickness. This is a clear indication of a second ring radial collapse immediately after the peak pressure in land one, in correspondence to the pressure drop seen in the first graph.

The gas flow rates from each groove are given in Fig. 10d.1, d.2. In particular, for the second case it is possible to see the fluctuation of the flow curve below the second groove, due to the radial collapse. The total amount of blowby gas lost in the crankcase is equal to $0.01242 \mathrm{~kg} /$ cycle for the $2000 \mathrm{rpm}$ case and $0.0048 \mathrm{~kg} /$ cycle for the $4500 \mathrm{rpm}$ case. The cycle time for the second case is almost a third of the first case, and for this reason the blow-by value is lower. In Fig. 10e, the piston velocity and acceleration for the 2000 and $4500 \mathrm{rpm}$ case are given. When the engine speed doubles, the acceleration increases by one order of magnitude according to the figure.

The analysis undertaken in this section referred to the effect of the mass and static twist variation of the top two rings. It is evident that the increment of the tension force gave better results for the top ring, which maintained a stable behavior in both axial and radial direction and at both speeds. The second ring, despite having had a greater increase of the tension force in comparison to the first ring, showed axial motion and a radial collapse when the speed increased. The increased axial motion must have been caused by the increased inertia force, while the radial motion causes are more complex. At the speed of $4500 \mathrm{rpm}$, the second ring moved to the groove upper flank in proximity to the combustion phase. When combustion occurred, the second land pressure increased, but since inertia was high enough to contrast the pressure force in the second land, the ring stayed up in its groove and blocked the gas flow. Under these conditions, the pressure force could not push the ring down, but pushed it inward in the groove, helped also by the taper face design of the second ring. These results are in line with the experiments cited in [13, 14], where the increase of engine speed and load increased the possibility of radial collapse. Despite the increase of the ring tension force, it was not enough to prevent the radial collapse of the second ring for the present engine. The importance of the ring's axial position on the radial collapse was also made evident in [13, 14], but the increased inertia force and the ring face design have introduced new variables to tackle with. It is evident that at higher speeds, the ring dynamics are more difficult to predict or control and require a multi-parameter approach.

\section{Static twist variation}

In this section, we discuss the simulation results for case 3 , when the static twists are varied according to Table 3.

In Fig. 11a.1, the inter-ring pressures obtained for the first case are given. When both the compression rings had positive twist angles, all the pressure curves had similar trends to the baseline case. The difference was in the lower peak pressures in the second and third land, and the explanation can be found in the ring locations in Fig. 11b.1. Differently from all the previous cases, the inner and outer diameters did not locate in the same position in their grooves, but remained twisted during the entire cycle. The top ring sat on the groove lower flank with its inner diameter until the beginning of the exhaust stroke, while the outer diameter varied its position in the groove. Due to this variation, the gas flow in the second land could exert its pressure and lift initially the outer ring diameter and subsequently the entire ring in correspondence to the crossover points. The inner and outer diameter of the second ring had a more remarkable difference in their position, as expected by the larger twist angle compared to the top ring. The inner diameter always sat down in the groove, while the outer diameter continuously lifted up, with lifts up to $30 \%$ of the groove height at the end of the compression stroke. In general, none of the rings took an extreme position in the groove, but were always free to move.

In Fig. 11a.2, the inter-ring pressures for case 2 are presented. When both static twists were set to negative values, the peak pressures in the second and third land were slightly higher with respect to the previous case. This is a clear indication that negative twisted rings are less efficient to block the gas flow in comparison to positive twisted rings. Figure $11 \mathrm{~b} .2$ shows the top two rings' location in the respective grooves. As in the previous case, the rings maintained their negative twist angle during the cycle, sitting in the grooves with their outer diameter and being lifted with their inner diameter. In comparison to the previous case, both rings had larger differences in their inner and outer diameter locations. Due to the negative twisted position, the high pressure gas 
(a1)

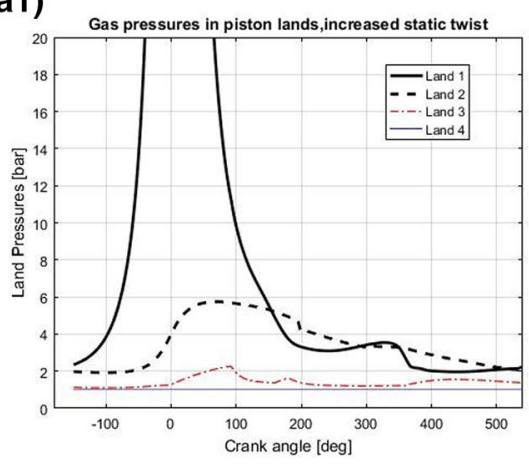

(b1)

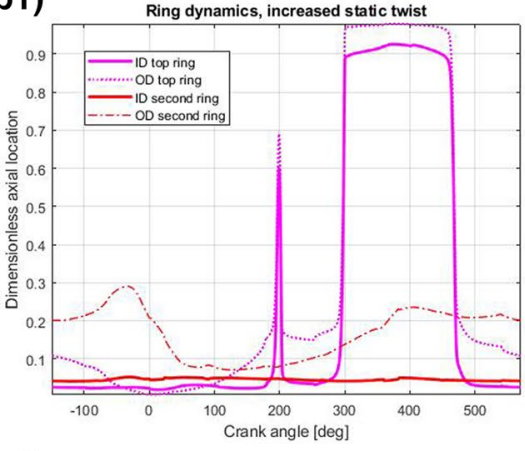

(c1)

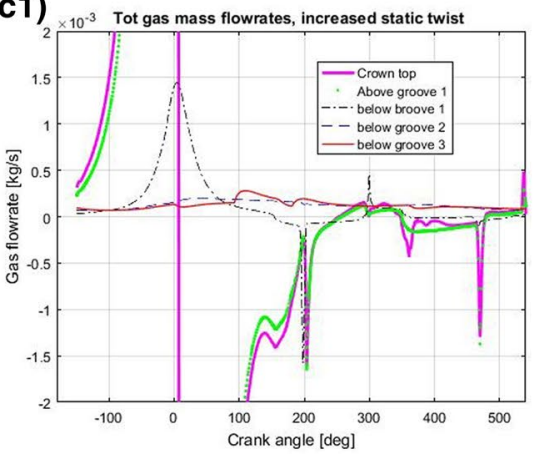

(a2)

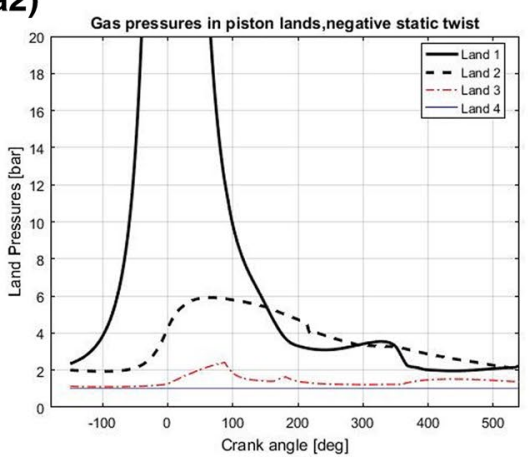

(b2)

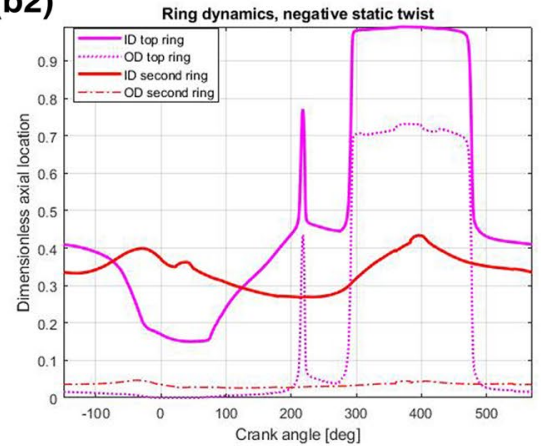

(c2)

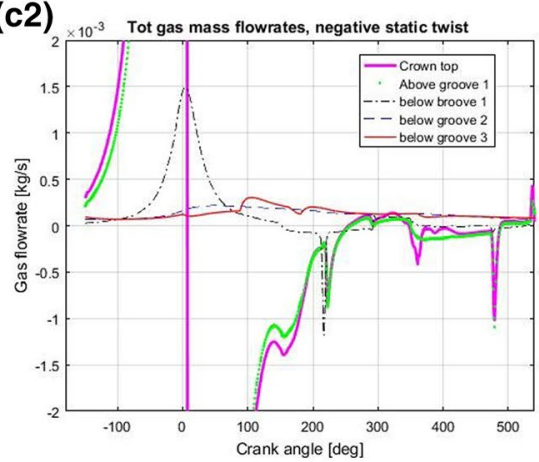

(a3)

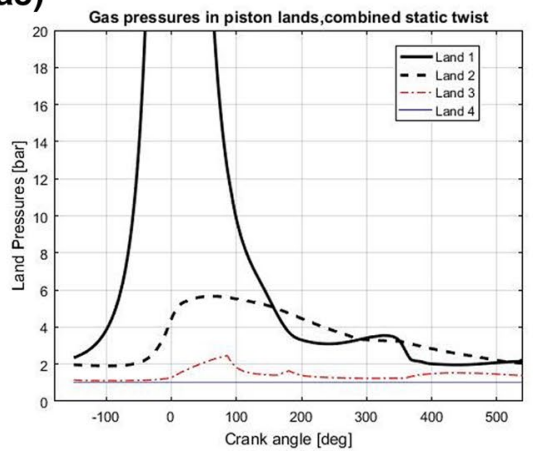

(b3)

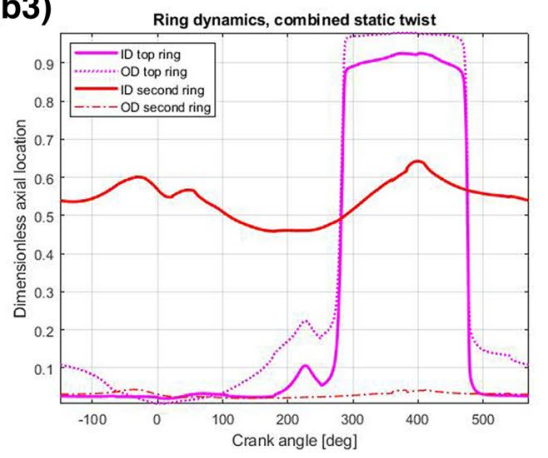

(c3)

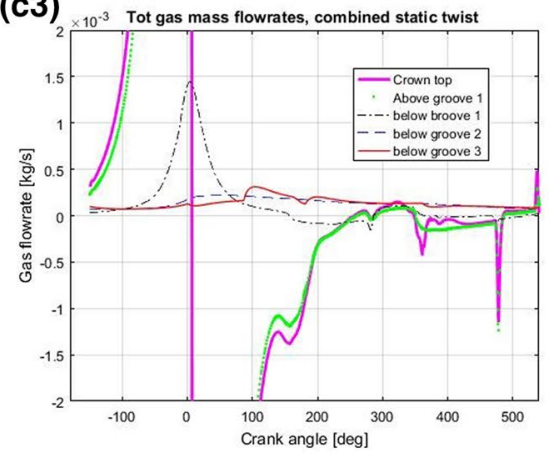

Fig. 11 Results for twist angle variation, case 3

of the top land entered into the top groove and pushed from below the top ring inner diameter, which was forced to lift and vary its location in the groove with a higher magnitude in comparison to the first case. As a result, the top ring could not properly seal the way of gas flow and a higher amount of gas entered in the second land. Since the second ring was also twisted negatively, the same discussion can be applied as above for the third land pressure.

Figure 11a.3 shows the inter-ring pressures for case 3, where ring static twists are varied in a combined way, positive twist for the top ring and negative twist for the second ring, as described in Table 3. The pressure in the second land is similar to the first case of this section, maintaining also the same trend. On the other hand, the pressure in the third land is higher in comparison to the first case and more similar to the second case. Ring lifts are presented in Fig. 11b.3, where the top ring maintained a positive twist angle, while the second ring maintained a negative twist angle along the entire cycle. The top ring did not exhibit the sharp lift at 200 crank angle degree as in the two previous cases, while the second ring inner diameter location was always lifted at the half groove height. The higher difference in the location between the inner and the outer diameters for the second ring was related to the higher twist angle $\left(-0.5^{\circ}\right)$ in comparison to the second case $\left(-0.3^{\circ}\right)$. Due to this configuration, the second ring sealing capability was further reduced, and a 
higher amount of gas could flow in the third land. As a consequence, the lower second land pressure was not able to lift the top ring at 200 crank angle, while the third land pressure was the highest of the three cases.

The axial location of the third ring was omitted from the discussion for the following reasons: first of all its twist angle was not changed; the second reason is related to the lower pressures acting above and below, which are not enough to constrain this ring as the former ones. Figure 11c.1-c.3 shows the gas flow rates for each case. The total amounts of blow-by gas in the crankcase are $0.0107705,0.011194$ and $0.011554 \mathrm{~kg} / \mathrm{cycle}$, respectively. According to the results, the best performance is reached in case one, when both rings have a positive static twist, while the worst performance in case three, when rings have combined static twists. In the middle is located the performance of the second case, when both rings have negative static twists. The result of case one matches the theoretical background and the results obtained in $[15,16]$; on the other side, the result of cases two and three were surprisingly inverted with respect to the expectations from literature.

During the simulations, none of the compression rings showed axial flutter or radial collapse, despite the large values of the twist angle. According to this discussion, the twist angle of the second ring had larger impact on the sealing capability of the entire ring pack. In particular, the negative angle has a detrimental effect, while the positive angle may bring positive effects.

\section{Comparative analysis}

Due to the large amount of data discussed in the upper sections, it is necessary to collect the blow-by results for all the cases and make a comparison between them. To increase clarity, in Fig. 12 all the results obtained from the simulations are given.

Fig. 12 Comparative results
Taking as a reference the baseline case, which corresponded to the original design, all the three parameters discussed above were able to impact the sealing behavior, but the ring gaps had the largest. Ring masses resulted to be a problem, because they promotes the ring motion due to inertia and removed the tightening benefits from the increased ring tension force. Positive twist angles had positive effect on the ring tightness, while negative twist angles have the opposite. The common line for the three cases is the interesting result of the second ring impact, which was not clearly stated in the reference literature. The first ring maintains the largest impact on blocking the gas flow from the combustion chamber, but as long as the focus of the paper was to investigate only the blow-by of the reference engine, the second ring played a more important role in this matter.

\section{Conclusion}

The present paper features the tightness analysis of a piston ring pack for automotive application. The system behavior is analyzed when three parameters are changed: the ring gaps, the ring masses and tension forces, and the ring static twists. The results obtained are in very good correlation with the literature. However, the following important outcomes emerge from the discussions:

- Inter-ring pressures and inter-ring dynamics were shown to influence each other in a direct manner.

- The top ring gap is important to control the gas escape from the combustion chamber to the lower lands, but the second ring gap is responsible for the amount of gas flow to the third land and the blow-by gas to the crankcase.

\section{Fig. 12 Comparative results}

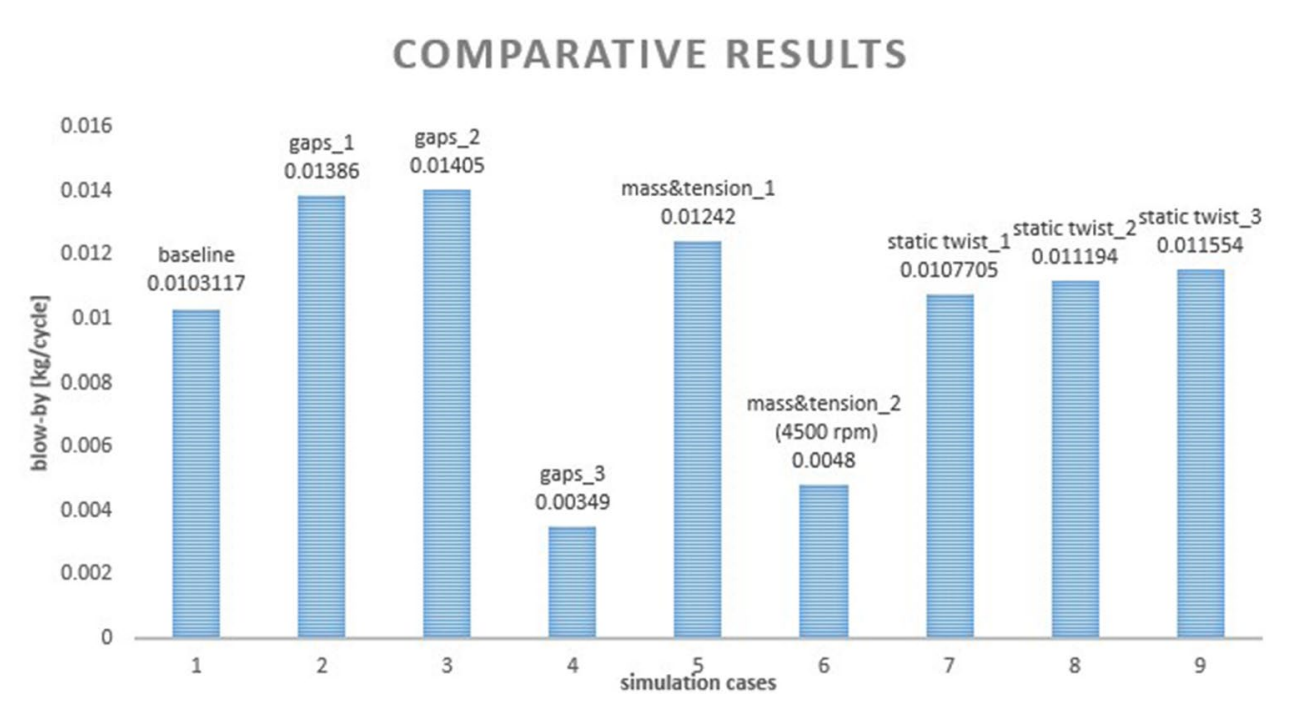


- Reduced top ring gaps help to achieve smaller second land pressures, but if the target is to reduce the blow-by, the second ring gap should be as small as possible.

- The inter-ring pressures are responsible for the inter-ring dynamics, in particular at low speed, when the inertia force acting on the ring is of low magnitude.

- The inertia force is proportional to the ring mass and the ring acceleration. Since the acceleration cannot be reduced because it is dependent on the engine speed, piston rings should be as light as possible.

- The tension force of the ring is important to always ensure a radial force and a correct conformation to the cylinder liner. An increased tension force is synonymous to a better sealing capability, but on the same time it may lead to increased friction losses.

- At high engine speed and load, the phenomenon of radial collapse is likely to occur. The study indicated that increasing the tension of the rings may not be enough to avoid the radial collapse, in particular for the present case where ring masses were doubled. Hence, it is necessary to investigate other parameters such as the ring face design and lubrication oil pattern.

- Negative static twist of the rings has a negative impact on the ring sealing capacity. As for the gap case, the second ring static twist is more important to control the blow-by gases.

- Positive static twists proved to have a positive impact on the system, due to a better ring-groove contact configuration. However, their real magnitude on the system should be studied in higher detail.

In this paper, only part of the parameters affecting interring dynamics, inter-ring pressures and gas flows have been considered. The results can be used for comparison with other cases, or as a tool for the analysis and design of new components, including spark ignition engines. However, the complete analysis can be further extended to other characteristics of the piston ring pack such as blow-back, pollution, oil consumption or power loss. To account for the complete system characteristics, further parameters such as piston and rings design, ring-liner conformability, piston secondary motion, cylinder bore distortion and surface properties should also be considered.

\section{Compliance with ethical standards}

Conflict of interest The authors declare that there is no conflict of interest with third parties or institutions and the outcome of the present work is the result of personal research.

Open Access This article is distributed under the terms of the Creative Commons Attribution 4.0 International License (http://creativeco mmons.org/licenses/by/4.0/), which permits unrestricted use, distribution, and reproduction in any medium, provided you give appropriate credit to the original author(s) and the source, provide a link to the Creative Commons license, and indicate if changes were made.

\section{References}

1. https://www.worldenergy.org/wp-content/uploads/2012/09/wec_ transport_scenarios_2050.pdf. Accessed Jan 2018

2. Zhao JX, Lee Chia-fon F (2006) Modeling of blow-by in a smallbore high-speed direct-injection optically accessible diesel engine. No. 2006-01-0649. SAE Technical Paper

3. Froelund K, Yilmaz E (2004) Impact of engine oil consumption on particulate emissions. In: ICAT international conference on automotive technology, Istanbul, Turkey

4. Green RM, Cloutman LD (1997) Planar LIF observations of unburned fuel escaping the upper ring-land crevice in an SI engine. SAE paper 970823

5. Alkidas, A.C.: Combustion-chamber crevices: the major source of engine-out hydrocarbon emissions under fully warmed conditions. Prog Energy Combust Sci 25(3), 253-273 (1999)

6. Arnault N, Bonne S (2012) Engine lube-oil consumption stakes and benefits from significant blow-by oil mist reduction. No. 2012-01-1617. SAE Technical Paper

7. Furuhama, S., Tosio, T.A.D.A.: On the flow of gas through the piston-rings: 2nd report, the character of gas leakage. Bull JSME 4(16), 691-698 (1961)

8. Namazian M, Heywood JB (1982) Flow in the piston-cylinder-ring crevices of a spark-ignition engine: effect on hydrocarbon emissions, efficiency and power. No. 820088. SAE Technical Paper

9. Keribar, Rifat, Dursunkaya, Zafer, Flemming, Michael F.: An integrated model of ring pack performance. ASME Trans J Eng Gas Turbines Power 113, 382-389 (1991)

10. Wannatong, Krisada, Chanchaona, Somchai, Sanitjai, Surachai: Simulation algorithm for piston ring dynamics. Simul Model Pract Theory 16(1), 127-146 (2008)

11. Makartchouk, Andrei: Diesel engine engineering - thermodynamics, dynamics, design, and control. Marcel Dekker Inc., New York (2002)

12. Tomanik E, Sobrinho RMS, Zecchinelli R (1993) Influence of top ring end gap types at blow-by of internal combustion engines. No. 931669. SAE Technical Paper

13. Iijima $\mathrm{N}$ et al (2002) An experimental study on phenomena of piston ring collapse. No. 2002-01-0483. SAE Technical Paper

14. Przesmitzki S, Tian T (2008) An Experimental study of the time scales and controlling factors affecting drastic blow-by increases during transient load changes in SI engines. No. 2008-01-0794. SAE Technical Paper

15. Tian, T.: Dynamic behaviours of piston rings and their practical impact. Part 1: ring flutter and ring collapse and their effects on gas flow and oil transport. Proc Inst Mech Eng Part J J Eng Tribol 216(4), 209-228 (2002)

16. Tian, T.I.A.N.: Dynamic behaviours of piston rings and their practical impact. Part 2: oil transport, friction and wear of ring/liner interface and the effects of piston and ring dynamics. Proc Inst Mech Eng Part J J Eng Tribol 216(4), 229-248 (2002)

17. Rabute, R., Tian, T.I.A.N.: Challenges involved in piston top ring designs for modern SI engines. Trans Am Soc Mech Eng J Eng Gas Turbines Power 123(2), 448-459 (2001)

18. Cheng, Chao, Schock, Harold, Richardson, Dan: The dynamics of second ring flutter and collapse in modern diesel engines. J Eng Gas Turbine Power 137(11), 111504 (2015) 
19. Yoshida H, Sugihara H, Kusama K (1995) Practical use of two piston ring set for gasoline engine. No. 950817. SAE Technical Paper

20. Delprete, C., Bisha, A., Selmani, E.: Gas escape from combustion chamber to crankcase, analysis of a set of parameters affecting the blow. International conference "new technologies, development and applications". Springer, Cham (2018)
21. Heywood, J.B.: Internal combustion engine fundamentals. McGraw-Hill, New York City (1988)

Publisher's Note Springer Nature remains neutral with regard to jurisdictional claims in published maps and institutional affiliations. 